\title{
$P-18$
}

\section{Uric acid in the follow-up determines 30\% decline in estimated GFR over 2 years: A propensity score analysis}

\begin{tabular}{|c|c|c|}
\hline Chang Wen $\mathrm{Xiu}^{1)}$ & $\mathrm{Xu} \mathrm{Ning}^{1)}$ & Yuan $\mathrm{Wei}^{1)}$ \\
\hline 田村 好古 2) & 熊谷 天哲2) & 柴田 \\
\hline
\end{tabular}

Background. The lower level of serum uric acid (SUA) predicts a longer dialysis-free survival time in patients with chronic kidney disease (CKD). However, a short-term effect of SUA remains to be elucidated using a novel surrogate renal endpoint.

Methods. CKD patients having repeated measurements over 2 years were enrolled $(\mathrm{n}=701)$. The time-toevent analysis was performed with a novel surrogate endpoint, $30 \%$ decline in eGFR over 2 years. The follow-up level of SUA was calculated as timeaveraged uric acid (TA-UA) using the trapezoidal rule. A propensity score (PS) for $6.0,6.5$ and $7.0 \mathrm{mg} / \mathrm{dL}$ of TA-UA was respectively calculated using baseline 23 covariates. Patients with unoverlapped PS were trimmed out and the remaining participants were divided into quintiles on PS and also subjected to PS matching.

Results. The incidence rate over 2 years was 90 of 440 in male vs. 36 of 261 in female ( $p=0.03$ ). The standard Cox regression failed to show the significance of baseline SUA. Stratified Cox regression on the quintile of the estimated PS showed that crude HRs of three thresholds $(6.0,6.5$ and $7.0 \mathrm{mg} / \mathrm{dL}$ ) were all significant (HR 2.44, 95\% CI 1.19-5.02; HR 2.52, 95\% CI 1.41-4.52; HR 2.44, 95\% CI 1.51-3.95, respectively). The HRs further adjusted for the covariates influencing the endpoint were likewise significant in all thresholds. KaplanMeier analysis after PS matching showed the significance in all thresholds ( $p=0.004, p=0.007$ and $p<0.001$ by stratified log-rank test, respectively). After PS matching, the average eGFR changes ( $\mathrm{ml} /$ $\mathrm{min} / 1.73 \mathrm{~m}^{2}$ over 2 years) between 2 groups showed the significance by paired $t$ test; $6.0 \mathrm{mg} / \mathrm{dL},-3.34$ and $-12.55, p<0.001, ; 6.5 \mathrm{mg} / \mathrm{dL},-5.22$ and -13.88 , $p=0.001 ; 7.0 \mathrm{mg} / \mathrm{dL},-10.23$ and $-20.16, p<0.001$.

Conclusions. Higher SUA increases likelihood of reaching a surrogate renal endpoint over 2 years. Early intervention for SUA $<6.0 \mathrm{mg} / \mathrm{dL}$ is needed for slowing CKD progression.
1 ) Department of Nephrology, Tianjin First Center Hospital, Tianjin, China

2 ) Department of Internal Medicine, Teikyo University School of Medicine, Tokyo, Japan
Chang Wen Xiu, Xu Ning, Yuan Wei, Shen Zhong Yang Yoshifuru Tamura, Takanori Kumagai, Shigeru Shibata, Yoshihide Fujigaki, Shunya Uchida 